\title{
In Vitro Production of Anti-RBC Antibodies and Cytokines in Chronic Lymphocytic Leukemia
}

\author{
W. Barcellini, ${ }^{\star}$ R. Montesano, G. Clerici, A. Zaninoni, F.G. Imperiali, R. Calori, A. Cortelezzi, \\ and A. Zanella \\ Dipartimento di Ematologia, IRCCS Ospedale Maggiore di Milano, Milan, Italy
}

\begin{abstract}
B-chronic lymphocytic leukemia (B-CLL) patients have a high prevalence of autoimmune phenomena, mainly autoimmune hemolytic anemia (AIHA). Immunoregulatory cytokines play a role in the regulation of both autoimmunity and leukemic B-cell growth. Mitogenstimulated direct antiglobulin test (MS-DAT) is a recently described test able to disclose latent anti-RBC autoimmunity in AIHA. We investigated the prevalence of anti-RBC autoimmunity by MS-DAT and the pattern of cytokine production by PHA-stimulated whole blood cultures from 69 B-CLL patients and 53 controls. Results showed that anti-RBC IgG values in unstimulated, PHA-, PMA-, and PWM-stimulated cultures were significantly higher in B-CLL patients compared with controls. In B-CLL, the prevalence of anti-RBC autoimmunity was $28.9 \%$ by MS-DAT, compared with $4.3 \%$ by the standard DAT. Production of IFN- $\gamma$, IL-2, IL-13, TNF- $\alpha, S C D 23$, and $S C D 30$ was significantly increased in all B-CLL patients compared with controls, whereas there was no difference in IL-4, IL-6, IL-10, and TGF- $\beta$ production. Multivariate analysis showed that IL-4 was significantly increased in MS-DAT-positive compared with -negative patients. Patients with autoantibody positivity displayed greater IFN- $\gamma$ production than negative patients. These data are in line with the hypothesis that autoimmune phenomena in B-CLL are associated with an imbalance towards a Th-2-like profile. The elevated prevalence of anti-RBC autoimmunity found by MS-DAT suggests that an underestimated latent autoimmunity exists in B-CLL. Am. J. Hematol. 71:177-183, 2002.
\end{abstract}

Key words: B-chronic lymphocytic leukemia (B-CLL); cytokines; autoimmunity; direct antiglobulin test (DAT)

\section{INTRODUCTION}

B-chronic lymphocytic leukemia (B-CLL) patients have a high prevalence of autoimmune phenomena due to polyclonal autoantibodies mainly restricted to blood cell self-antigens [1]. Autoimmunity has been related to B-CLL biological properties and cellular origin as well as to microenvironmental factors. The malignant cell is a mantle-zone-like CD5+ B cell, which is normally devoted to the production of polyreactive natural autoantibodies. These cells are in the G0 phase of the cell cycle, but express activation membrane molecules such as CD23, CD27, and CD30 and are able to secrete a variety of cytokines. The precise role of these environmental factors is still unclear. Some cytokines, including TNF- $\alpha$, IL-1, IL-2, IL-4, and IFN- $\gamma$ have been proposed as autocrine growth-promoting factors, through prevention of apoptosis [2-5]. On the contrary, other cytokines may be responsible for negative autocrine circuits. IL-10 inhibits the in vitro PMA- and PMA plus anti-Ig-induced proliferation of leukemic B-cells [6] and promotes apoptosis [7]; IL-6 is an inhibitory factor for TNF- $\alpha$-induced B-cell proliferation [8]. Bone marrow stromal cells from B-CLL patients produce increased amounts of TGF- $\beta$ [9], which likely exerts an inhibiting activity on hematopoietic precursors; however, peripheral B-cells from patients lack responsiveness to the antiproliferative and pro-apoptotic effects of TGF- $\beta$, probably because of decrease or loss of TGF- $\beta$ receptor expression [10].

*Correspondence to: W. Barcellini, Dipartimento di Ematologia, Padiglione Granelli, Ospedale Maggiore di Milano, Via F. Sforza 35, 20122 Milano, Italy. E-mail: wbarcel@polic.cilea.it

Received for publication 15 April 2002; Accepted 15 July 2002

Published online in Wiley InterScience (www.interscience.wiley.com). DOI: 10.1002/ajh.10210 
In spite of the growing evidence on the effect of exogenous cytokines on leukemic cells, there are conflicting reports regarding cytokine production in B-CLL. PHA-stimulated cultures of T cells from B-CLL patients show increased production of IL-2, IL-4, IFN- $\gamma$, and TNF- $\alpha[11,12]$. At variance, intracellular IL-4 and IFN- $\gamma$ are reduced in CD4+ T cells from patients [13]. Production of IL-6 is decreased in PMA- and PMA plus IL-2stimulated PBMC from patients in advanced disease stage [14]. On the contrary, serum levels of IL-6 and IL-10 are elevated and correlate with adverse disease features and short survival [15].

Autoimmune responses are controlled by complex regulatory circuits, which also involve immunoregulatory cytokines [16]. Several sources of evidence support the idea that T-helper (Th)-1-inducing cytokines (IL-2, IL-12, IFN- $\gamma$ ) can upregulate T-cell autoimmunity, whereas cytokines that promote Th- 2 differentiation (IL4, IL-6, IL-13, IL-10) and downregulate Th-1 responses (TGF- $\beta$, IL-4) are invariantly associated with protection from autoimmune diseases. However, there are several exceptions to these scenarios, which indicate a prevalent Th-2 profile in systemic autoimmune diseases [16]. Autoimmune hemolytic anemia (AIHA) is the most frequent autoimmune complication of B-CLL. In AIHA Th-2 (IL4, IL-6, IL-13) cytokines are elevated and Th-1 is reduced. We recently described a new method for the detection of anti-RBC antibodies in mitogen-stimulated whole blood cultures, termed mitogen-stimulated direct antiglobulin test (MS-DAT). The test was suitable for revealing cytokine modulation of anti-RBC antibody production and disclosing a latent autoimmunity, since mitogen stimulation induced antibody production in AIHA in clinical remission [17].

The aim of this study was to investigate the prevalence of anti-RBC autoimmunity by MS-DAT and to study patterns of in vitro cytokine production by PHAstimulated whole blood cultures from B-CLL patients. Th-1 (IL-2, IFN- $\gamma$ ), Th-2-like (IL-4, IL-6, IL-10, IL-13), proinflammatory (TNF- $\alpha$ ), inhibitory (TGF- $\beta$ ) cytokines, and soluble activation markers (sCD23, sCD30) were correlated with anti-RBC autoimmunity, disease stage, and therapy.

\section{MATERIALS AND METHODS}

\section{Patients}

Sixty-nine patients with B-CLL (mean age \pm SD $68 \pm$ 11 years, range $41-89,25$ female and 44 male) and 53 age- and sex-matched healthy regular blood donors were studied as controls. B-CLL was diagnosed according to defined clinical, morphological, and immunological criteria [18]. Patients were staged according to the guidelines proposed by Binet et al [19].

\section{Reagents}

Phorbol-12-myristate-13-acetate (PMA) and phytohemagglutinin (PHA) were from Sigma-Aldrich Chemicals (St. Louis, MO); pokeweed (PWM) from Gibco Laboratories (Grand Island, NY). Commercial monoclonal reagents (anti-IgG+C, anti-IgG, anti-C3d, and anti-C3c) rabbit antihuman $\operatorname{IgA}$ and sheep antihuman $\operatorname{IgM}$ were from Ortho (Raritan, NJ), Bioscot (Edinburgh, UK), and Gamma (Houston, TX) were used for tube-DAT.

\section{DAT and Nonorgan-Specific Autoantibody Determination}

Tube-DAT was performed according to standard techniques using both polyspecific and monospecific sera [20]. The cassette-DAT (BioVue Ortho) was carried out with monospecific antiserum only, following the manufacturer's instructions. The presence of rheumatoid factor (RF), antinuclear (ANA), antimitochondrial (AMA), antismooth muscle (SMA), anticardiolipin (ACA), antithyroid peroxidase (TPO), antithyreoglobulin, anti-dsDNA, and anti-extractable nuclear antigens (ENA), namely, Sm, nRNP, SSA-Ro, SSB-La, Scl-70, and Jo-1 antibodies were determined by commercially available ELISA kits according to conventional techniques.

\section{Culture Conditions}

Fresh heparinized blood samples were diluted 1:6 with RPMI 1640 medium (Gibco) and either unstimulated or stimulated with mitogens and/or cytokines in 24-well plates and incubated for $48 \mathrm{hr}$, according to previous experiments [21-23]. Forty-eight-hour cultures were stimulated with $2 \mu \mathrm{g} / \mathrm{ml}$ PHA, $20 \mathrm{ng} / \mathrm{ml}$ PMA, $1 \%$ PWM. After 48-hr culture, RBC were washed four times with phosphate-buffered saline (PBS), centrifuged at $1,000 \mathrm{rpm}$ for $10 \mathrm{~min}$, resuspended in PBS at $10 \%$ concentration, and processed for the quantitation of antiautologous RBC bound IgG, as detailed below.

\section{Anti-RBC-Bound IgG Quantitation}

The quantitation of RBC-bound IgG was evaluated with a competitive solid-phase enzyme immunoassay, as previously described [17]. Briefly, 96-well plates were coated with $50 \mu \mathrm{l}$ of human $\operatorname{IgG}$ overnight at $4^{\circ} \mathrm{C}$, then $3 \times$ washed, and blocked with $200 \mu \mathrm{l}$ of $2 \%$ FCS-PBS for $2 \mathrm{hr}$ at room temperature. A standard curve was constructed with group $0 \mathrm{CcDee}$ RBC $(200 \mu \mathrm{l}$ of $10 \%$ suspension in $0.2 \%$ FCS-PBS) sensitized with serial dilutions $(4,000-37.5 \mathrm{ng} / \mathrm{ml})$ of anti-Rh antibody (Immuno AG, Vienna, Austria) for $1 \mathrm{hr}$ at $37^{\circ} \mathrm{C}$. The cell suspension was then $3 \times$ washed and incubated with peroxidaseconjugated rabbit antihuman IgG (Dako, Denmark) diluted $1: 3,000$ in $0.2 \%$ FCS-PBS at $37^{\circ} \mathrm{C}$ for $30 \mathrm{~min}$. One hundred $\mu \mathrm{l}$ of this mixture were added to the IgG-coated plates and incubated at $37^{\circ} \mathrm{C}$ for $30 \mathrm{~min}$. After $5 \times$ 
washes, $50 \mu \mathrm{l}$ of o-phenylenediamin dihydrochloride was added to each well. The colorimetric reaction was measured at $450 \mathrm{~nm}$ after $15 \mathrm{~min}$ with an ELISA spectrophotometer. For determination of anti-RBC on autologous cultured $\mathrm{RBC}$, cultured cell suspensions were treated as anti-Rh-sensitized CcDee RBC. Briefly, the cell culture suspension was $3 \times$ washed, incubated with peroxidase-conjugated rabbit antihuman $\operatorname{IgG}$ for $30 \mathrm{~min}$, added to the IgG-coated plates, and further incubated for $30 \mathrm{~min}$. After $5 \times$ washes the colorimetric reaction was evaluated. A $\log / \log$ plot was constructed with OD values and anti-Rh antibody concentration of the standard curve $(\mathrm{ng} / \mathrm{ml})$, and autologous anti-RBC-bound IgG value was calculated referring to this standard curve. To determine a cutoff for MS-DAT positive values, the mean of PHA-, PMA-, and PWM-stimulated cultures of controls was calculated and the positivity for MS-DAT defined as a value exceeding the mean plus $3 \mathrm{SD}$ of controls (220 IgG ng/ml).

\section{Cytokine and Soluble Activation Markers Production}

Cytokine production was measured in 48-hr PHAstimulated culture supernatants using commercially available ELISA kits according to the manufacturers' instructions. IL-2, IL-4, IL-13, IFN- $\gamma$, TGF- $\beta$ were purchased from Amersham Pharmacia Biotech (Buckinghamshire, UK) and TNF- $\alpha$, IL-6, IL-10 from Cytimmune (College Park, MD). sCD23 from Bender Medical Systems (Vienna, Austria) and sCD30 from Dako A/S (DK2600, Glostrup, Denmark).

\section{Statistical Analysis}

Univariate analysis was performed by means of unpaired Student's test for unequal variances. Multivariate analysis was performed by means of multiple logistic regression using the SAS package, v. 7.0 (SAS, Cary, NC). Comparisons between values at baseline and after stimulation were performed by two-tailed Student's $t$-test for paired data. Probability values $<0.05$ were considered statistically significant.

\section{RESULTS}

\section{Clinical and Laboratory Characteristics of B-CLL Patients}

At the time of the study, 24 patients were in Stage A, 21 in $\mathrm{B}$, and 14 in C. Mean disease duration \pm SE was 22 \pm 4.5 months (range 1-219). Stage A and B patients were either untreated ( $n=29$ and $n=4$, respectively), treated with chlorambucil $(\mathrm{n}=5$ and $\mathrm{n}=13$ ), or fludarabine ( $\mathrm{n}$ $=0$ and $n=4$ ); one of the fludarabine-treated patients also received CEOP chemotherapy. Stage $\mathrm{C}$ patients were treated with chlorambucil alone or associated with prednisone $(n=6)$, fludarabine $(n=7)$, and CEOP $(\mathrm{n}=1)$; one of the fludarabine-treated patients also received cyclophosphamide chemotherapy.

The leukocyte and absolute lymphocyte number of patients was $18,069 \pm 1,936 / \mu \mathrm{l}$ and $12,278 \pm 1,602 / \mu \mathrm{l}$ (mean \pm SE of Stage A patients, respectively), 32,931 \pm $6,474 / \mu 1$ and $24,697 \pm 5,549 / \mu 1$ (Stage B patients), and $23,685 \pm 7,914 / \mu l$ and $13,281 \pm 5,307 / \mu l$ (Stage C patients). Twelve Stage $\mathrm{C}$ patients had anemia $(\mathrm{Hb}<10$ $\mathrm{g} / \mathrm{dl}$ ) and 21 patients (9 Stage A, 12 Stage B) have mild anemia (female: $\mathrm{Hb} 10-11.5 \mathrm{~g} / \mathrm{dl}$; male: $\mathrm{Hb} 10-13 \mathrm{~g} / \mathrm{dl}$ ). As far as classic hemolytic signs are concerned (reticulocyte count greater than $2 \%, \mathrm{LDH}$ greater than $460 \mathrm{U} / 1$, and haptoglobin lower than $600 \mathrm{mg} / \mathrm{l}$ ), only the latter was considered for B-CLL patients, since LDH could be elevated and reticulocytes reduced because of lymphoproliferative disease and bone marrow failure, respectively. Thirteen (three Stage A, five Stage B, and five Stage C) had anemia (female: $\mathrm{Hb}<11.5 \mathrm{~g} / \mathrm{dl}$; male: $\mathrm{Hb}<13 \mathrm{~g} / \mathrm{dl}$ ) with haptoglobin levels below the normal range. Three Stage C patients suffered from DAT-positive-AIHA and were being treated with HD-chlorambucil and prednisone; $2 / 3$ were still DAT-positive, whereas one became DAT-negative at the time of the study. The prevalence of AIHA in our series was therefore $4.3 \%$.

\section{MS-DAT in B-CLL Patients}

Figure 1 shows the amount of anti-RBC IgG in unstimulated and mitogen-stimulated cultures from B-CLL patients and controls. Anti-RBC IgG values were significantly higher in B-CLL patients compared with controls in all the experimental conditions tested $(P=0.002$ for unstimulated cultures, $P=0.0004$ for PHA- and PWMstimulated cultures, $P=0.01$ for PMA-stimulated cultures). Mitogen stimulation had no effect in controls, whereas it significantly increased anti-RBC IgG value in B-CLL patients $(P=0.001$ and 0.04 for PHA and PWM, respectively). MS-DAT was positive in $20 \mathrm{~B}-\mathrm{CLL}$ patients (ten in Stage A, four in Stage B, six in Stage C), corresponding to a prevalence of $28.9 \%$.

To ascertain whether MS-DAT positivity was associated with other autoimmune markers, determination of serum autoantibodies was carried out in 42 B-CLL patients. We found 14 positive patients $(33 \%)$ - three RF, three ANF, one SMA, one ACA, two anti-TPO, three antithyreoglobulin, and one anti-dsDNA; $3 / 14$ were also MS-DAT-positive.

Multivariate analysis showed no relationship between MS-DAT positivity and all the clinical and laboratory parameters considered (age, sex, disease duration, and therapy; WBC, lymphocyte, RBC, and reticulocyte counts, $\mathrm{Hb}, \mathrm{Ht}$, haptoglobin, $\mathrm{LDH}$, bilirubin levels, and autoantibody positivity). 


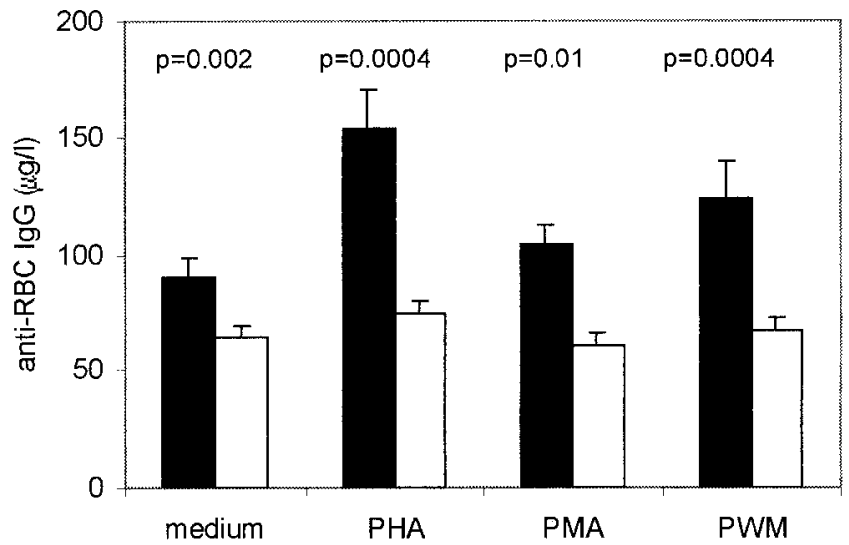

Fig. 1. Effect of mitogen stimulation on in vitro autologous anti-RBC bound IgG values in B-CLL patients and controls. Autologous anti-RBC bound IgG values were assessed in 48-hr whole blood cultures and expressed as $\lg \mathrm{G} \mu \mathrm{g} / \mathrm{l}$, mean ะ SE of 69 patients (solid bars) and 53 controls (open bars). Statistically significant comparisons of B-CLL cultures vs. controls are indicated.

\section{Cytokine Production in Whole Blood Cultures From B-CLL Patients}

As shown in Table I, production of IL-2, IFN- $\gamma$, TNF$\alpha$, and IL-13 was significantly increased in B-CLL patients compared with controls. There was no difference in IL-4, IL-6, IL-10, and TGF- $\beta$ production. The increased production of IL- 2 , IFN- $\gamma$, TNF- $\alpha$, and IL-13 was restricted to Stage A and B patients. Stage C patients displayed IL-2, IFN- $\gamma$, TNF- $\alpha$, and IL-13 values significantly decreased compared with Stage A patients. To ascertain whether therapy could have affected cytokine production, untreated and treated (chlorambucil, prednisone, fludarabine, and other) patients were compared. No difference was found in IFN- $\gamma$, IL-2, IL-10, IL-13, TNF- $\alpha$, IL-4, IL-6, and TGF- $\beta$ production (data not shown). At variance, by comparing fludarabine-treated vs. the other patients, production of all the cytokines investigated was reduced (on average 50\%) in the former. In particular, IL-2 production was significantly reduced in the fludarabine-treated group compared with the other patients $(295 \pm 209$ vs. $1,112 \pm 112 \mathrm{pg} / \mathrm{ml}$, mean \pm SE of 11 and 58 patients, respectively, $P=0.003$ ).

Along with cytokine production, sCD23 and sCD30 levels were investigated in PHA-stimulated culture supernatants (Table I). Both soluble markers were significantly increased in B-CLL patients compared with controls. No clear relationship with disease stage was observed for sCD23, whereas a clear increase in Stage C was found for sCD30. Considering the relationship between cytokine production and soluble CD markers, values of sCD23 were positively correlated with those of IFN- $\gamma(\mathrm{r}=0.623, P=0.001)$ and IL-10 $(\mathrm{r}=0.467$, $P=0.001)$.

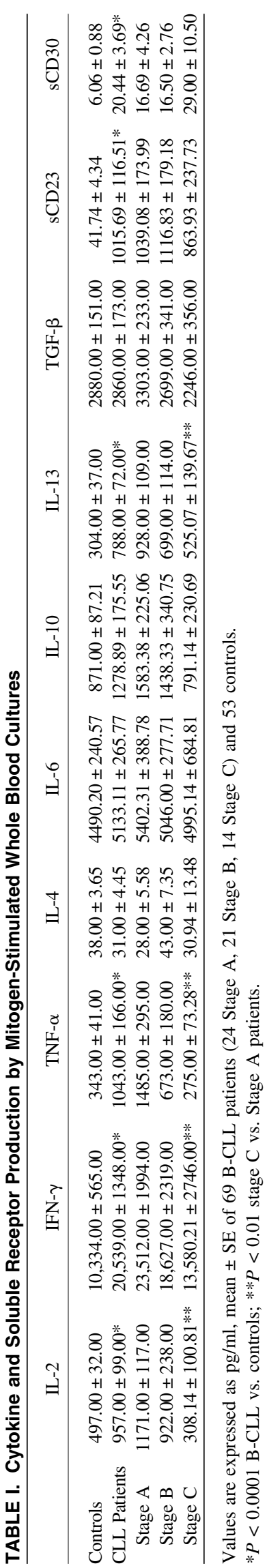



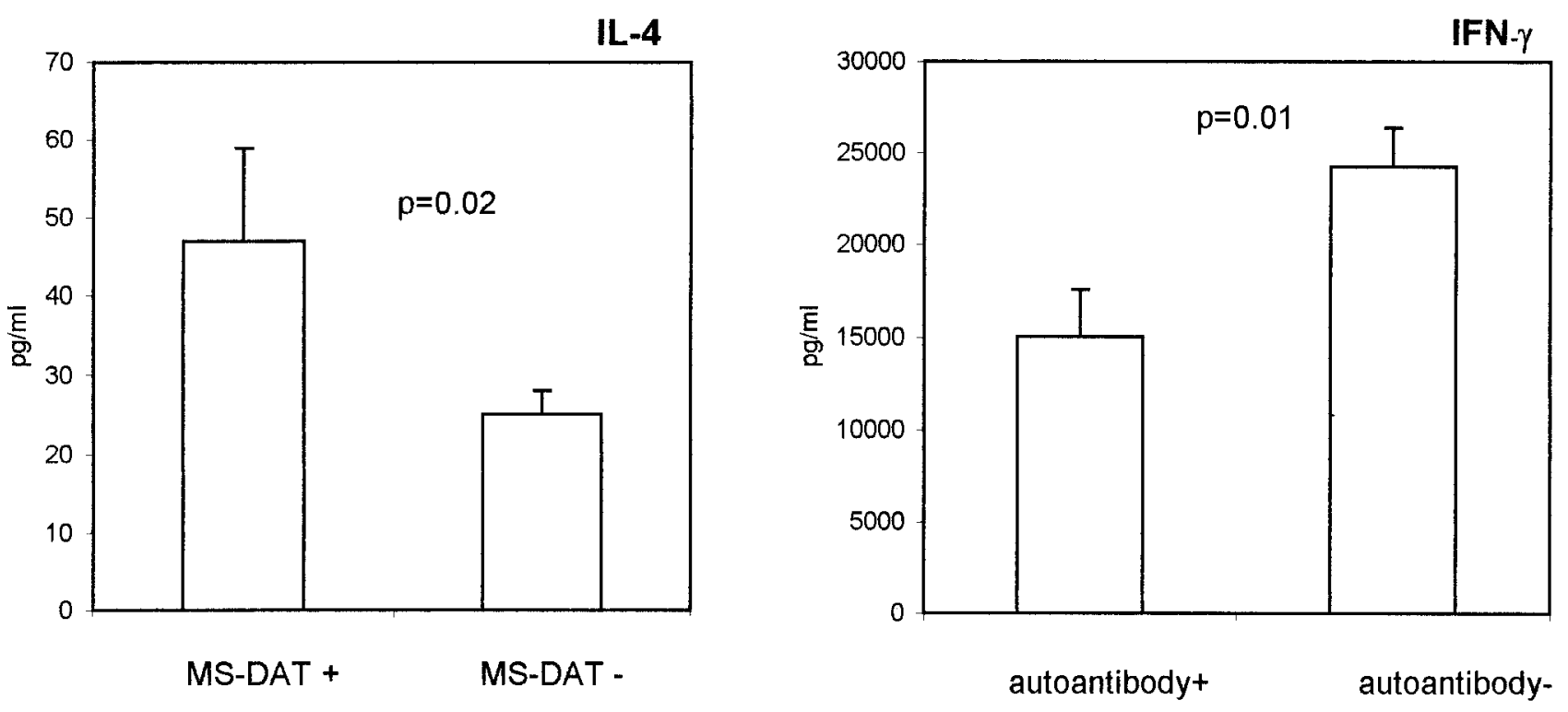

Fig. 2. IL-4 and IFN- $\gamma$ production in B-CLL patients with MS-DAT or autoantibody positivity. Cytokine production was assessed in PHA-stimulated 48-hr whole blood cultures from B-CLL patients. Values are expressed as pg/ml, mean $\pm \mathrm{SE}$ of 69 patients. Statistically significant comparisons are shown.

As far as MS-DAT positivity is concerned, patients with positive values of anti-RBC IgG displayed increased values of PHA-stimulated IL-4 production compared with MS-DAT-negative patients (Fig. 2, left). Multivariate analysis and maximum likelihood estimates showed that IL-4 was significantly increased in MSDAT-positive compared with negative patients $(P=$ 0.0017). No difference in the other cytokines, sCD23, and sCD30 values were found between MS-DATpositive and -negative subjects. Patients with autoantibody positivity displayed lower IFN- $\gamma$ production than negative patients (Fig. 2, right). No difference in the other cytokines, sCD23, and sCD30 values were found.

\section{DISCUSSION}

The results show that autoimmune phenomena, either directed against RBC or other autoantigens, are frequent in B-CLL patients, in line with previous findings [24,25], but in disagreement with Hamblin et al. [26], who found high levels of autoantibodies, but no higher than in agematched controls. Here we show that the prevalence of anti-RBC autoimmunity estimated by MS-DAT is even greater (roughly six times) than that estimated by the standard DAT. This finding suggests that mitogen stimulation is able to disclose a latent autoimmunity in B-CLL, as shown in AIHA [17].

Since immunoregulatory cytokines are involved in the pathogenesis of autoimmunity and AIHA, we asked whether a different cytokine pattern could be found in B-CLL patients with or without anti-RBC autoimmunity. To this end, in the same mitogen-stimulated whole blood cultures in which MS-DAT was determined, we investigated cytokine secretion. First, the whole B-CLL population was considered. An increased production of IL-2, IFN- $\gamma$, TNF- $\alpha$, and IL-13 was found, whereas secretion of IL-4, IL-6, IL-10, and TGF- $\beta$ was comparable to controls. Our findings are in agreement with those of Reyes et al. [11], who showed increased production of IL-2, IFN- $\gamma$, and TNF- $\alpha$ by T-cells. IFN- $\gamma$ was reported to inhibit apoptosis [4] and TNF- $\alpha$ and IL-2 to act as autocrine growth-promoting factors of leukemic B-cells $[2,5]$. Therefore, the increased production of these cytokines could contribute to the accumulation of leukemic B-cells. IL-13, a Th-2-like cytokine, is a growthpromoting factor for B-normal lymphocytes stimulated with anti-IgM antibody and induces the expression of CD23 [27]. Even if its effects on the leukemic B-cells need to be studied, the increased production of this Th2-like cytokine could contribute to the expansion of leukemic B-cells. In addition, it has been reported that IL-13 induces IFN- $\gamma$ production by NK cells [27], which in turn could exert further antiapoptotic effects on leukemic B-lymphocytes.

Considering cytokine production in B-CLL patients with positivity for MS-DAT or serological autoantibodies, we found increased IL-4 in the former and reduced IFN- $\gamma$ production in the latter. These data are in line with the hypothesis that autoimmune phenomena in B-CLL are associated with an imbalance towards a Th-2-like profile. Increased IL-4 and reduced IFN- $\gamma$ has been documented in the paradigmatic autoimmune disease SLE, consistent with the prevalent humoral autoimmunity observed in this disease [28]. Furthermore, increased 
IL-4 was found in AIHA, both in vivo [29,30] and in vitro [17], in line with the immunopathogenic mechanism involved in RBC destruction, i.e., complementmediated autoantibody lytic activity and antibodydependent cellular cytotoxicity.

As far as the activation markers investigated are concerned, we found increased SCD23 production in mitogen-stimulated cultures of B-CLL patients, in line with several reports in the literature [31-34]. However, contrary to what was found in sera, in culture supernatants there was no relationship with disease stage. Likewise, sCD30 was increased in mitogen-stimulated cultures of B-CLL patients compared with controls, particularly in advanced stage patients. Our results are in line with previous findings indicating that this TNF-superfamily ligand is involved in B-CLL pathogenesis, both in maintaining neoplastic growth and regulating the apoptotic phenomena [35-37]. Notwithstanding several reports on the role of CD23 and CD30 in autoimmunity [38-42], our results showed no difference in sCD23 and sCD30 between B-CLL patients with or without autoimmune features.

Our results demonstrate a high prevalence of anti-RBC autoimmunity by MS-DAT in B-CLL. We do not know why the cells can be driven to make RBC autoantibodies in vitro, but not in vivo. However, the ability of mitogen stimulation to induce antibody production suggests that an underestimated latent autoimmunity exists in B-CLL. The clinical and prognostic significance of these data is still uncertain. There was no relationship between MSDAT positivity and disease stage, hemolytic parameters, or positivity for other serological markers of autoimmunity. In any case, it should be noted that, 3 months after the end of the study, one of the MS-DAT-positive patients developed DAT-negative hemolytic anemia which recovered after steroid administration. Furthermore, another MS-DAT-positive patient developed autoimmune thrombocytopenia and DAT-negative hemolytic anemia and died of rapidly progressive disease with infective complications.

\section{CONCLUSION}

The high prevalence of anti-RBC autoimmunity by MS-DAT suggests the existence of an underestimated latent autoimmunity in B-CLL. MS-DAT positivity could have a predictive value on the development of AIHA or autoimmune complications; a longer clinical follow-up and study of a larger series of patients could confirm this capability. The imbalance towards a Th-2like cytokine profile in B-CLL with autoimmune features suggests hints for the future development of anticytokine treatment in B-CLL.

\section{REFERENCES}

1. Caligaris-Cappio F. Relationship between autoimmunity and immunodeficiency in CLL. Hematol Cell Ther 1998;39:S13-S16.

2. Cordingley FT, Bianchi A, Hoffbrand AV, Reittie JE, Heslop HE, Vyakarnam A, Turner M, Meager A, Brenner MK. Tumour necrosis factor as an autocrine tumour growth factor for chronic B-cell malignancies. Lancet 1988;1:969-971.

3. Dancescu M, Rubio-Trujillo M, Biron G, Bron D, Delespesse G, Sarfati M. Interleukin 4 protects chronic lymphocytic leukemic B cells from death by apoptosis and upregulates Bcl-2 expression. J Exp Med 1992;176:1319-1326.

4. Buschle M, Campana D, Carding S, Richard C, Hoffbrand A, Brenner M. Interferon $\mathrm{g}$ inhibits apoptotic cell death in B cell chronic lymphocytic leukemia. J Exp Med 1993;177:213-218.

5. Larsson LG, Carlsson M, Schena M, Lantz M, Caligaris-Cappio F, Nilsson K. Interleukin-2 enhances the production of tumor necrosis factor- $\alpha$ in activated B-type chronic lymphocytic leukemia (B-CLL) cells. Leukemia 1993;7:226-234.

6. Tangye SG, Weston KM, Raison RL. Interleukin-10 inhibits the in vitro proliferation of human activated leukemic CD5+ B-cells. Leuk Lymphoma 1998;31:121-130.

7. Fluckiger AC, Durand I, Banchereau J. Interleukin 10 induces apoptotic cell death of B-chronic lymphocytic leukemia cells. J Exp Med 1994;179:91-99.

8. Aderka D, Maor Y, Novick D, Engelmann H, Kahn Y, Levo Y, Wallach D, Revel M. Interleukin-6 inhibits the proliferation of B-chronic lymphocytic leukemia cells that is induced by tumor necrosis factoralpha or beta. Blood 1993;81:2076-2084.

9. Lagneaux L, Delforge A, Dorval C, Bron D, Stryckmans P. Excessive production of transforming growth factor-beta by bone marrow stromal cells in B-cell chronic lymphocytic leukemia inhibits growth of hematopoietic precursors and interleukin-6 production. Blood 1993; 82:2379-2389.

10. Lagneaux L, Delforge A, Bernier M, Stryckmans P, Bron D. TGF-beta activity and expression of its receptors in B-cell chronic lymphocytic leukemia. Leuk Lymphoma 1998;31:99-106.

11. Reyes E, Prieto A, Carriòn F, Garcia-Suarez J, Esquivel F, Guillen C, Alvarez-Mon M. Altered pattern of cytokine production by peripheral blood CD2+ cells from B chronic lymphocytic leukemia patients. Am J Hematol 1998;57:93-100.

12. De Totero D, Reato G, Mauro F, Cignetti A, Ferrini S, Guarini A, Gobbi M, Grossi CE, Foa R. IL-4 production and increased CD30 expression by a unique $\mathrm{CD} 8^{+} \mathrm{T}$-cell subset in B-cell chronic lymphocytic leukemia. Br J Haematol 1999;104:589-599.

13. Hill SJ, Peters SH, Ayliffe MJ, Merceica J, Bansal AS. Reduced IL-4 and interferon-gamma (IFN- $\gamma$ ) expression by CD4 T cells in patients with chronic lymphocytic leukaemia. Clin Exp Immunol 1999;117:811.

14. Hulkkonen J, Vilpo J, Vilpo L, Hurme M. Diminished production of interleukin-6 in chronic lymphocytic leukaemia (B-CLL) cells from patients at advanced stages of disease. Br J Haematol 1998;100:478483.

15. Fayad L, Keating MJ, Reuben JM, O’Brien S, Lee BN, Lerner S, Kurzrock R. Interleukin-6 and interleukin-10 levels in chronic lymphocytic leukemia: correlation with phenotypic characteristics and outcome. Blood 2001;97:256-263.

16. Falcone M, Sarvetnick N. Cytokines that regulate autoimmune responses. Curr Opin Immunol 1999;11:670-676.

17. Barcellini W, Clerici G, Montesano R, Taioli E, Morelati F, Rebulla P, Zanella A. In vitro quantification of anti-red blood cell antibody production in idiopathic autoimmune haemolytic anaemia: effect of mitogen and cytokine stimulation. Br J Haematol 2000;111:452-460.

18. Cheson BD, Bennett JM, Grever M, Kay N, Keating MJ, O'Brien S, Rai KR. National Cancer Institute-sponsored working group guide- 
lines for chronic lymphocytic leukemia: revised guidelines for diagnosis and treatment. Blood 1996;87:4990-4997.

19. Binet JL, Auquier A, Dighiero G, Chastang C, Piguet H, Goasguen J, Vaugier G, Potron G, Colona P, Oberling F, Thomas M, Tchernia G, Jacquillat C, Boivin P, Lesty C, Duault, MT, Monconduit M, Belabbes S, Gremy F. A new prognostic classification of chronic lymphocytic leukemia derived from a multivariate survival analysis. Cancer 1981; 48:198-206.

20. Walker RH. Technical manual. Arlington, VA: American Association of Blood Banks; 1996.

21. Barcellini W, Sguotti C, Dall'Aglio P, Garelli S, Meroni PL. In vitro immunoglobulin synthesis: T-cell requirement in pokeweed and staphylococcus aureus B-cell activation. J Clin Lab Immunol 1985;17:177181.

22. Barcellini W, Rizzardi GP, Borghi MO, Fain C, Lazzarin A, Meroni PL. TH1 and TH2 cytokine production by peripheral blood mononuclear cells from HIV-infected patients. AIDS 1994;8:757-762.

23. Barcellini W, Rizzardi GP, Velati C, Borghi MO, Fain C, Lazzarin A, Meroni PL. In vitro production of type 1 and type 2 cytokines by peripheral blood mononuclear cells of HIV-1-negative intravenous drug users. AIDS 1995;9:691-694.

24. Jonsson V, Svendsen B, Vorstrup S, Krarup C, Schmalbruch H, Thomsen K, Heegard NH, Wiik A, Hansen MM. Multiple autoimmune manifestations in monoclonal gammopathy of undetermined significance and chronic lymphocytic leukemia. Leukemia 1996;10:327332.

25. Mauro FR, Foa R, Cerretti R, Giannarelli D, Coluzzi S, Mandelli F, Girelli G. Autoimmune hemolytic anemia in chronic lymphocytic leukemia: clinical, therapeutic, and prognostic features. Blood 2000;95: 2786-2792.

26. Hamblin TJ, Oscier DG, Young BJ. Autoimmunity in chronic lymphocytic leukemia. J Clin Pathol 1986;39:713-716.

27. Zurawski G, De Vries JE. Interleukin 13, an interleukin 4-like cytokine that acts on monocytes and B cells, but not on T cells. Immunol Today 1994;15:19-26.

28. Funauchi M, Ikoma S, Enomoto H, Horiuchi A. Decreased Th1-like and increased Th2-like cells in systemic lupus erythematosus. Scand J Rheumatol 1998;27:219-224.

29. Fagiolo E, Vigevani F, Pozzetto U. High cytokine serum levels in patients with autoimmune haemolytic anaemia (AIHA). Immunol Invest 1994;23:449-456.

30. Fagiolo E, Abenante L. Lymphocyte activation and cytokine production in autoimmune haemolytic anaemia (AIHA). Autoimmunity 1996; 24:147-156.

31. Reinisch W, Willheim M, Hilgarth M, Gasche C, Mader R, Szepfalusi
S, Steger G, Berger R, Lechner K, Boltz-Nitulescu G. Soluble CD23 reliably reflects disease activity in B-cell chronic lymphocytic leukemia. J Clin Oncol 1994;10:2146-2152.

32. Sarfati M, Chevret S, Chastang C. Prognostic importance of serum soluble CD23 in chronic lymphocytic leukemia. Blood 1996;88:42594264.

33. Molica S, Levato D, Dell'Olio M, Matera R, Minervini M, Dattilo A, Carotenuto M, Musto P. Cellular expression and serum circulating levels of CD23 in B-cell chronic lymphocytic leukemia. Implications for prognosis. Haematologica 1996;81:428-433.

34. Keating MJ. Chronic lymphocytic leukemia. Semin Oncol 1999;26: 107-114.

35. Gattei V, Degan M, Gloghini A, De Iuliis A, Improta S, Rossi FM, Aldinucci D, Perin V, Serraino D, Babare R, Zagonel V, Gruss HJ, Carbone A, Pinto A. CD30 ligand is frequently expressed in human hematopoietic malignancies of myeloid and lymphoid origin. Blood 1997;89:2048-2059.

36. Horie R, Gattei V, Ito K, Imajo-Ohmi S, Tange T, Miyauchi J, Pinto A, Degan M, De Iuliis A, Tassan-Mazzocco F, Rossi FM, Higashihara $\mathrm{M}$, Watanabe T. Frequent expression of the variant CD30 in human malignant myeloid and lymphoid neoplasms. Am J Pathol 1999;155: 2029-2041.

37. Cerutti A, Kim EC, Shah S, Schattner EJ, Zan H, Schaffer A, Casali P. Dysregulation of CD30+ T cells by leukemia impairs isotype switching in normal B cells. Nat Immunol 2001;2:150-156.

38. Al-Janadi M, al-Wabel A, Raziuddin S. Soluble CD23 and interleukin-4 levels in autoimmune chronic active hepatitis and systemic lupus erythematosus. Clin Immunol Immunopathol 1994;71:33-37.

39. Barcellini W, Rizzardi GP, Borghi MO, Nicoletti F, Fain C, Del Papa $\mathrm{N}$, Meroni PL. In vitro type-1 and type- 2 cytokine production in systemic lupus erythematosus: lack of relationship with clinical disease activity. Lupus 1996;5:139-145.

40. Caligaris-Cappio F, Bertero MT, Converso M, Stacchini A, Vinante F, Romagnani S, Pizzolo G. Circulating levels of soluble CD30, a marker of cells producing Th2-type cytokines, are increased in patients with systemic lupus erythematosus and correlate with disease activity. Clin Exp Rheumatol 1995;13:339-343.

41. Ebo D, DeClerck LS, Bridts CH, Stevens WJ. Expression of CD5 and CD23 on B cells of patients with rheumatoid arthritis, systemic lupus erythematosus and Sjogren's syndrome. Relationship with disease activity and treatment. In Vivo 1994;8:577-580.

42. Ichikawa Y, Yoshida M, Yamada C, Horiki T, Hoshina Y, Uchiyama M. Circulating soluble CD30 levels in primary Sjogren's syndrome, SLE and rheumatoid arthritis. Clin Exp Rheumatol 1998;16:759-760. 